\title{
Análise das Principais Teorias de Organização
}

\author{
CAPÍtULO III
}

Orǵanização de cima para baixo: A Concepção Anatômica (1)

\section{BEATRIZ M. DE SOUza WaHRLich}

\begin{abstract}
A esccla "anatômica" se preocupa com a forma e a disposição organizacional e com as interrelações estruturais das partes.
\end{abstract}

Deve-se muito da literatura sôbre organização a esta escola, que dá ênfase à análise dos problemas de organização de cima para baixo, contrastando com o ponto de vista dos engenheiros. Os anatomistas de organização são decididamente "administrativamente orientados"; (2) olham a organização como um "sistema de subdividir a emprêsa, sob o chefe principal." (3)

DWIGHT WALDO oferece outra classificação possível para esta escola: formam seus componentes o grupo racionalista. WALDo quer dizer, com o têrmo racional, que "ela (a escola) tendia a salientar o poder da razão humana de assenhorear-se dos elementos constitutivos das relações humanas e de manejar essas relações de forma lògicamente traçada para atingir objetivos predeterminados". (4) Esta classificação, contudo, implica numa crítica que, seja qual fôr o seu mérito, não cabe nesta parte. Mais tarde, todavia, será novamente mencionada.

Os principais elementos que contribuiram para a formação da escola "anatômica" foram FAYOL, Gulick, MOONEY, SchUYLER WALlace.

A contribuição de FAYOL foi, primeiramente, apresentada em 1908, (5) e continua, ainda, muito viva, embora já tenha sido absorvida, alterada e aper-

(1) Esta classificação se deve ao Professor Sterling Spero.

(2) Ideas and Issues in Public Administration, Dwight WALDo, p. 103.

(3) LUTHER Gulick, "Notes on the Theory of Organization", in Papers on the Science of Administration, p. 11.

(4) Op. cit. p. 103.

(5) Conferência pronunciada na Sociedade de Indústria Mineira (Society for Mining Industry), publicada em seu Boletim em 1951; sob a forma de livro em 1925; tôdas as citações feitas aqui foram tiradas da tradução inglêsa, "General and Industrial Manasement", 1949. 
feiçoada pcr outros representantes da escola. Seu livro "Administração Geral e Industrial" se desdobra em três partes distintas :

1. ${ }^{\text {) }}$ necessidade e possibilidade do ensino de administração;

2. ${ }^{\text {a }) ~ u m a ~ a n a ́ l i s e ~ d o s ~ p r i n c i ́ p i o s ~ g e r a i s ~ d e ~ a d m i n i s t r a c ̧ a ̃ o ; ~ e ~}$

3. a) uma discussão dos elementos de administração. (6) A primeira foge, nìtidamente, ao escopo dêste trabalho, que se ocupa de uma seção da segunda parte (aquela que trata dos princípios de administração aplicáveis a organização) e de uma seção da terceira parte (aquela que trata a organização como um elemento da administração).

\section{O QUE É ORGANIZAÇÃo?}

De acôrdo com FAYOL,

organizar significa construir a dupla estrutura, material e humana, do empreendimento.... Se fôsse possível deixar de levar em conta o fator humano, seria bastante fácil construir uma unidade social orgânica. Qualquer principiante poderia fazê-lc, desde que tivesse algumas idéias das práticas usadas e pudesse contar com os necessários recursos. Mas para se criar uma organização útil não basta grupar pessoas e distribuir deveres; deve haver um conhecimento de como adaptar o todo orgânico às necessidades, bem ccmo encontrar o elemento humano essencial e colocar cada um onde fôr mais imprescindível; em suma, numerosas qualidades são indispensáveis. (7)

Segundo as palavras de URwICK, não conseguiu FAYoL fazer uma distinção clara entre o delineamento da estrutura duma emprêsa e o provimento do pessoal para executar os várics grupos de atividades assim demarcados... Justamente porque FAYOL era um homem prático, de longa experiência, essa atitude provàvelmente era inevitável. O administrador de responsabilidade não pode divorciar-se do fator humano. As emprêsas constituem-se de elementos humanos, empenhados num empreendimento comum e assim possuem características de organismos vivos. Considerá-las puramente mecânicas é abrir uma porta a tôda espécie de êrro. Mas, no que tange à pretensão de que o trabalho de FAYoL tenha estabelecido uma teoria de administração - pretensão que foi certamente advogada por seus discípulos - seu conceito de organização estabelece limites que restringem o seu próprio pensamento. E impossível, para a humanidade, aprofundar seu conhecimento de organização, a não ser que o fator estrutura seja isolado de cutras considerações, ainda que tal separação possa parecer artificial. (8)

(6) A êsse respeito, FAYOL pronunciou também um discurso perante o " $2^{\text {nd }}$ International Congress of Administrative Sciences", em Bruxelas, 1923 (in Papers on the Scienceof Administration, pp. 101-114).

(7) General and Industrial Management, pp. 6 e 57.

(8) "The Function of Administration", in Papers on th Science of Administration, pp. 121-122. 
Constitui esta a principal, diferença entre a conceituação de FAYOL e a de outros elementos dêsse grupo. Tanto Gulick como Mooney isolaram o. fator "estrutura" da crganização; a definição de Gulick já foi citada, (9) e a de Mooney é a seguinte:

Organização é a forma de tôda associação humana para a realização de um fim comum... A técnica de organização pode ser descrita como a técnica de correlacionar atividades específicas ou funções num todo coordenado. (10)

Contudo, White acrescenta uma palavra de precaução:

... o ponto vital é que estrutura é um arranjo das relações de trabalho de indivíduos e não simplesmente um processo impessoal de unir tijolos para construir um edifício. Sendo um sistema de ordenação de seres humanos, está sujeita, em determinados casos, a modificações que as possíveis combinações de personalidades. possam exigir. Dum certo ponto de vista, organização é um sistema formal e declarado de relações, que pode ser representado, embora imperfeitamente, por um quadro ou por um organograma. Encarado dum ângulo mais realístico tem um caráter psicológico: constituir um agrupamento constante e habitual de relações humanas, resultante da interação mútua de pessoas que trabalham juntas. (11)

\section{COMO ORGANIZAR?}

Em sua análise dos "princípios de administração", FAYOL inclui diversas normas aplicáveis ao processo de organização; no capítulo em que estuda a organização como um elemento da administraçãc, discute também êsse assunto. Êste estudo se inicia com aquêles dentre seus "princípios de administração" que são aplicáveis à tarefa de organizar: divisão do trabalho, autoridade, unidade de comando, unidade de direção, centralização, escala hierárquica cu hierarquia, "esprit de corps". (12)

De acôrdo com FAyol, o objetivo da divisão do trabalho é a especialização. Como tal, "pertence à ordem natural". (13) Gulick tem a mesma reação quando diz que "a divisão do trabalho constitui a base da organização; na verdade, é a própria razão da organização". (14) Gulick contribui para a harmonia de pontos de vista, ao afirmar que o trabalho deve ser dividido, porque

os homens diferem em natureza, capacidade e habilidade, e ganham, grandemente, em destreza, pela especialização;... o mesmo

(9) Veja anotação. (3)

(10) The Principles of Organization, edição revista, pp. 1 e 3.

(11) Introduction to the Study of Public Administration, p. 26.

(12) General and Industrial Management, pp. 19-20.

(13) Ibid., p. 20.

(14) "Notes on the Theory of Organization, in "Papers on the Science of Administration", p. 3. 
homem não pode estar em dois lugares ao mesmo tempo;... o campo do conhecimento e da técnica é tão grande que um homem, dentro de espaço de sua vida, não pode conhecer dêle senão uma pequena fração. Noutras palavras, é uma questão de natureza humana, tempo e espaço. (15)

\section{COMO DIVIDIR O TRABALHO?}

Segundo os membros desta escola, o trabalho deve ser dividido de duas maneiras : atendendo acs graus de autoridade e à correspondente responsabilidade (a "escala hierárquica ou hierarquia" (16) de FAYOL, e "princípio escalar" de Mooney); (17) e de acôrdo com a distinção entre tipos de atividades (a "especialização", (18) de FAYOL, o "princípio funcional", de MooNEY (19) e o "princípio de homogeneidade", de GulICK). (20) URWICK também endossa essas idéias, ao expressar :

Em organização o grupamento de atividades se processa sempre em dois sentidos contrários : um, em que as linhas divisórias são verticais, indicando tipos ou variedades de atividades; e cutro, no qual as linhas delimitadoras são horizontais, indicando níveis de autoridade. E impossivel definir qualquer atividade, precisamente, em qualquer organização, sem enquadrá-la nesses dois sentidos, da mesma maneira que é impossível fixar um ponto num mapa ou numa carta a não ser em têrmos de suas coordenadas. (21)

\section{COMO DIVIDIR O TRABALHO $\grave{A}$ BASE DA AUTORIDADE E DA RESPON- SABILIDADE?}

FAyol e MOONEy afirmam que a maneira adequada de dividir o trabatho, à base da autoridade cu responsabilidade, é conferindo "o direito de dar ordens e o poder de exigir obediência", (22) através da "outorga de uma determinada medida de autoridade por uma autoridade mais elevada" (23) (a primeira constitui a definição de "autoridade" de FAYOL e a segunda o conceito de "delegação", de MOONEy). HenRy E. Niles acrescenta alguns conselhos :

... a responsabilidade pela execução das várias atividades necessárias à consecução do objetivo da organização deve ser distribuí-

(15) Ibid.

(16) Op. cit. p. 34 .

(17) The principles of Organization, edição revista, p. 14.

(18) General Industrial Management, p. 20.

(19) Op. cit., p. 25.

(20) "Notes on the Theory of Organization", in Papers on the Science of Administration, p. 9.

(21) The Elements of Administration, p. 47.

(22) FAYOL, op. cit., p. 21.

(23) MOONEY, op. cit., p. 17. 
da de tal maneira que haja um mínimo de interferências e cruzamento de relações.

... a responsabilidade deve ser expressamente delegada;

... a responsabilidade deve ser claramente definida, de maneira que o ponto de resolução possa ser fixado prontamente. (24)

Continuando a enunciar e definir seus princípios relativos a autoridade e responsabilidade, lembra FAYOL - e com êle concorda GuLICK - dois aspectos essenciais, em relação à unidade de comando;

para qualquer ação, qualquer que seja ela, um empregado só deve receber ordens de um único superior; (25)

desde os mais remotos tempos, tem sido reconhecido que nada, a não ser confusão, resulta da multiplicidade de ccmando. (26)

CAtheryn Seckler-Hudson concorda, plenamente, com Fayol e Gulick, quando diz: “... unidade de comando... deve impregnar tôda a organização". (27)

Até que ponto o trabalho deve ser dividido à base da autoridade e responsabilidade? Até que ponto se deve descentralizar?

FAyol diz que

centralizar ou descentralizar é, simplesmente, uma questão de proporção, é um problema de encontrar o grau "ideal" para cada caso em particular... Se a envergadura moral do chefe, sua capacidade, sua inteligência, sua experiência e sua agilidade mental the permitirem estender bastante sua ação pessoal, poderá levar muito longe a centralização e reduzir seus empregados à condição de simples agentes executivos; se, ao contrário, prefere, reservando para si o privilégio de traçar as diretrizes gerais, apelar mais para a experiência, opinião e conselhos de seus colaboradores, pode efetuar uma ampla descentralização." (28)

Sôbre o mesmo assunto REDFIELD escreve que

uma descentralização administrativa eficaz depende: primeiro, da vontade dos superiores de delegar e, em seguida, de sua capacidade de fazê-lo. Tal vontade é, em grande parte, psicológica, refletindo a experiência que o delegante tenha tido no passado. (29)

Catheryn Seckler-Hudson é favorável à descentralização:

... a autoridade e a correspondente responsabilidade devem ser delegadas e localizadas, o mais perto possível, do ponto em que se realizam as operações. (30)

(24) Processes of Organization and Management, pp. 49-50.

(25) FAYOL, General and Industrial Management, p. 24.

(26) LUTHER Gulick, "Notes on the Theory of Organization", in Papers on the Science of Administration, p. 9.

(27) In Processes of Organization and Management, p. 43.

(28) Op. cit. p. 33.

(29) Comunication in Management, p. 253.

(30) In Processes of Organization and Management, p. 42. 
E esta também a opinião de HENRY E. NILES quando escreve :

.... Os problemas devem ser resolvidos, e as decisões tomadas, no nível mais baixo possível da organização; ou, em outras palavras, a decisão e a coordenação devem ter lugar, tanto quanto possível, no próprio ponto da ação. (31)

Mas o tema autoridade e responsabilidade nunca foi tão bem exposto quanto nas palavras de JETHRO a Morsés, às quais foi dada particular atenção não só por URWICK como por MoONEY, em sua análise de delegação de autoridade :

"E aconteceu que, ao outro dia, MoIsÉs assentcu-se para julgar o povo; e o povo estava em pé diante de Morsés desde a manhã até a tarde;

Vendo pois o sogro de Morsés tudo o que êle fazia ao povo, disse: "Que é isto, que tu fazes ao povo? por que te assentas só, e todo o povo está em pé diante de ti, desde a manhã até a tarde?

Então disse MoIsÉs a seu sogro: É porque êste povo vem a mim, para consultar a Deus;

Quando tem algum negócio vem a mim, para que eu julgue entre um e outro, e lhes declare os estatutos de Deus, e as suas leis. O sogro de Morsés porém the disse: não é bom o que fazes.

Totalmente desfalecerá, assim tu, como êste povo que está contigo: porque êste negócio é mui difícil para ti; tu só não o podes fazer. Ouve agora minha voz, eu te aconselharei, e Deus será contigo. Sê tu pelo povo diante de Deus e leva tu as coisas a Deus;

E declara-lhes os estatutos e as leis e faze-lhes saber o caminho em que devem andar, e a obra que devem fazer.

$\mathrm{E}$ tu dentre todo o povo procura homens capazes, tementes a Deus, homens de verdade, que aborrecem a avareza; e põe-nos sôbre êles por maiorais de mil, maiorais de cento, maiorais de cinquienta, e maiorais de dez;

Para que julguem êste povo em tempo; e seja que todo o negócio pequeno êles o julguem; assim a ti mesmo te aliviarás da carǵa, e êles a levarão contigo. Se isto fizeres, e Deus te mandar poderás então subsistir; assim também todo êste povo em paz virá ao seu lugar.

E MorsÉs deu ouvidos à voz do seu sogro, e fêz tudo quanto tinha dito.

$\mathrm{E}$ escolheu MoIsÉs homens capazes de todo o Israel, e os pôs por cabeças sôbre o povo: maiorais de mil, maiorais de cento, maiorais de cinqüenta, e maiorais de dez.

E êles julgaram o povo em todo o tempo; o negócio árduo trouxeram a Morsés, e todo o negócio pequeno julgaram êles.

Então despediu MorsÉs o seu sogrc o qual se foi à sua terra." (32)

(31) Ibid. p. 50.

(32) Exodus, 18. 


\section{COMO DIVIDIR O TRABALHO DE ACÔRDO COM A DIFERENCIAÇÁO ENTRE OS DIVERSOS TIPOS DE TAREFAS?}

FAyol não contribui para o esclarecimenta dêste assunto.

Gulick diz que a situação ideal, quanto à homogeneidade, verá reunidos, na mesma unidade, todos aquêles que estiverem executando:

o mesmo trabalho, pelo mesmo processo, para a mesma clientela, o mesmo lugar... Quando qualquer um dêsses quatro fatôres varia, torna-se necessária uma seleção para determinar a qual dêles se deve dar precedência, na delimitação do que é e do que não é homogêneo e portanto combinável. (33)

A escolha das bases para obter homogeneidade resulta na organização por objetivo, prccesso, clientela ou material, ou área.

Organização por objetivo dominante, como abastecimento de água, contrôle da criminalidade, ou educação, serve para reunir num único grande departamento todos aquêles que trabalham na consecução de um determinado serviço... Organização pcr processo dominante, como engenharia, ensino, direito ou medicina, tende a reunir num único departamento todos os que trabalham utilizando-se duma técnica ou habilitação especial, ou então que sejam elementos integrantes de uma determinada profissão... Organização à base das pessoas atendidas ou das pessoas com as quais se lida, ou à base das coisas com que se lida, conduz à reunião, num único departamento, independentemente da finalidade do serviço, ou da técnica utilizada, de todos aquêles que trabalham com um determinado grupo de pessoas cu coisas...

Organização à base do local em que o serviço é executado reune, todos aquêles que trabalham, numa determinada área, seja qual fôr o serviço que estejam desempenhando cu a técnica que representem. (34)

\section{SCHUYLER WALlace afirma :}

por certc, cada uma dessas definições revela as qualidades essenciais do método de organização que se propõe descrever. E fora de dúvida, também, que, à base dessas definições, torna-se possível identificar muitos dos departamentos administrativos, hoje existentes nos diferentes países. Não menos indubitável, contudo, é que essas definições não conseguem delinear, claramente, os limites entre os diversos conceitos, tornando-se, em conseqüência, responsáveis por uma considerável parcela da falta de clareza e confusão que caracterizam grande parte da discussão abstrata sôbre o assunto. (35)

(33) Op. cit. p. 15.

(34) Gulick, Papers in the Science of Administration, pp. 21-26.

(35) Federal Departmentalization, pp. 91-146. A critique of Theories of Organization, p. 94. 
Após apresentar e analisar um exemplo, continua WALLACE:

À luz desta análise, somos inevitàvelmente levados a perguntar se haverá utilidade numa discussão abstrata de tais conceitos, assim mal definidos e pobremente delineados...

A pergunta dá idéia de uma confusão muito maior do que na realidade existe. Isto porque, embora se deva admitir que as definições geralmente aceitas são um tanto insatisfatórias, ou por não conseguirem fornecer critéricis concretos para sua aplicação, ou pela falta de nitidez na caracterização de seus limites, existe, contudo, em relação a cada um dêsses conceitos, uma essência real de significado. Assim, embora essas generalizações raramente mereçam a qualificação de "princípios de administração", deve-se todavia darlhes um lugar proeminente entre os fatôres que concorrem para o estabelecimento de uma organização departamental. (36)

WALLACE continua analisando as condições sob as quais se deve preferir um critério a outros, examinando exaustivamente as vantagens e desvantagens dos padrões organizacionais resultantes. Em resumo, embora com mais cautela, endossa êle, certamente, as bases de departamentalizaçãc, discutidas por Gulick.

MOoNEY adota um ponto de vista diferente. Em sua opinião, a distinção entre variedades de atividades - ou "diferenciação funcional" - leva à identificação de três grupos principais: o discriminativo, o aplicativo e o interpretativo, ou seja, funções ligadas à definição do objetivo, funções referentes à sua consecução e funções relativas às decisões interpretativas. (37)

Não se pode conceber trabalho, função ou tarefa individual, de qualquer espécie, que não envolva um dos três elementos: a determinação de alguma coisa a ser feita, a feitura dessa coisa e a decisão de questões que possam surgir no curso da em que essa coisa é executada, em obediência a normas e práticas predeterminadas. (38)

Êstes são os "denominadores comuns" da grande variedade de funções existentes em tôda parte. (39)

URWICK concorda tanto com Mooney quanto com Gulick. Está de acôrdo com Mooney quando diz que

... enquanto as funções específicas podem ser de variedade quase infinita, dependendo da complexidade das atividades necessárias à obtenção de um determinado fim, não se concebe nenhuma função ou mesmo tarefa isolada de qualquer espécie que não se enquadre numa daquelas três classes. $\mathrm{E}$ essas três classes se relacionam no que se refere a princípio, processo e resultado. Dizem respeito, res-

(36) Op. cit., pp. 96.

(37) The Principles of Organization, revised edition, pp. 25-26.

(38) Ibid., p. 27.

(39) Ibid, pp. 25-27. 
pectivamente, a um dos três fatos: determinação de que alguma coisa seja feita; execução dessa coisa; e decisão de casos que surjam ao executá-la, de acôrdo com regras e preceitos prefixados.

Essas classes de atividades ou são determinativas, ou aplicativas, ou interpretativas. (40)

E concorda com Gulick e WALLACE, ao continuar dizendo :

O número mais avultado de atividades encontradas na maioria das formas de organização pertence ao grupo aplicativo ou executivo. $\mathrm{E}$ é, consequientemente, em função da execução, ou seja, do trabalho a ser feito, que normalmente se expressa a diferenciação funcional.

Segue-se daí que o processo de definição consiste na identificação dos limites de cada cargo, de cada grupo de atividades... Três métodos gerais de determinação de tais limites existem na prática: o unitário, o seriado e "subjectival"... (*) De acôrdo com o método unitário, determinam-se os limites de cada grupo de atividades, tomando-se por base pessoas, coisas cu áreas...

O método seriado... se apresenta quando, por exemplo, um produto passa por uma série de departamentos, cada qual equipado para realizar um determinado processo ou grupo de processos... Finalmente, há o método "subjectival", muitas vêzes chamado "funcional", de distribuir atividades. Neste caso, os limites de cada cargo são fixados tendo em conta ou um determinado assunto ou um aspecto da administração, ou, ainda, um grupo de assuntos correlatos. (41)

Torna-se evidente que o método unitário constitui a departamentalização por clientela, por material ou por área; o método seriado é a departamentalização por processo ou técnica; e o método "subjectival" a departamentalização por objetivo.

\section{AtÉ ONDE SE DEVE LEVAR A DEPARTAMENTALizaÇÃo?}

A divisão do trabalho de acôrdo com o princípio da homogeneidade não deve prosseguir incontidamente. Restringe-a o princípio do alcance de contrôle, de que Gulick diz:

"Exatamente como a mão do homem só pode alcançar um número limitado das teclas de um piano, assim também a mente e a von-

(40) The Elements of Administration, pp. 53-54.

(*) Buscou o autor na palavra "subject" a origem para a denominação dada ao seu terceiro método. Como dentre as acepções da palavra "subject" destacam-se "assunto", "matéria", "objeto", podemos dizer que o método "subjectival" é o que toma por base um determinado assunto. Aliás, a outra designação dada a esse mesmo método, ou seja, "funcional" e a descrição que dêle faz no texto o autor dispensariam talvez esta Notas Sentímo-nos, contudo, no dever de fazê-la.

Não existindo o têrmo "subjectival" nem mesmo em inglês, pareceu-nos um pouco de exagero procurar encontrar um equivalente em nossa língua.

Por isso julgamos mais razoável conservá-lo no original. (N.T.)

(41) Ibid., ps. 56-60. 
tade de um homem só podem alcançar um número restrito de contatos administrativos... O limite do contrôle constitui, em parte, uma questão de limitação do conhecimento; mais ainda, porém, é uma questão de limite de tempo e energia. Em conseqüência, o chefe de qualquer emprêsa só pode dar ordens pessoalmente a uns poucos indivíduos... Essa situação imposta a tôda organização humana pelos limites do alcance de contrôle não é a mesma, é óbvio, para diferentes espécies de trabalho e para organizações de variadas proporções. Onde o trabalho é rotineiro, repetitivo, de caráter e natureza mensuráveis, talvez um homem possa dirigir númerosos operários... Onde o trabalho é diversificado, de qualidade e sobretudo quando as pessoas que o executam estão dispersas, um homem poderá supervisionar sòmente a poucos." (42)

URWICK é ainda mais enfático a êsse respeitc; afirma, categòricamente, que "nenhum chefe pode supervisionar diretamente o trabalho de mais do que cinco, ou, no máximo, seis subordinados cujo trabalho seja interrelacionado". (43)

E URwick menciona o ensaio no qual GraICUNAS dramatiza, através de análise matemática, $\mathrm{c}$ impacto causado sôbre o chefe pelas relações diretas e cruzadas com seus subordinados. (44)

Henry Niles é também a favor do princípio do "alcance de contrôle". Afirma que um "chefe graduado só deve ter, comunicando-se consigo, diretamente, um pequeno número de pessoas; em geral, não mais que cinco, às vêzes um número maior". (45)

LEONARD WhITE, ccntudo, declara :

"o número máximo de subordinados que um chefe é capaz de supervisionar, com resultado, não pode ser determinado pela aplicação de uma "lei" do alcance da atenção. O verdadeiro contrôle da atenção varia com o tipo de trabalho supervisionado (quer seja rotineiro, quer seja aquêle em que se tenha que tomar decisões), com o nível de responsabilidade, com a personalidade de chefe e chefiados e com o necessário grau de supervisão e direção." (46)

Nem FAyol, nem Mooney incluem o "alcance de contrôle" em sua discussão dos princípios de organização.

\section{COMO COORDENAR?}

FAYoL não classifica como princípio de administração a "coordenação", de que, entretanto, faz uma análise exaustiva, como um elemento de adminis-

(42) "Notes on the Theory of Organization", in Papers on the Science of Administration, p. 7 .

(43) The elements of Administration, pp. 52-53.

(44) "Relationships in Organization," in Papers on the Science of Administration, pp. 183-187.

(45) Processes of Organization and Management, p. 50.

(46) Introduction to the Study of Public Administration, p. 57. 
tração. Por coordenação entende: "a reunião, a unificação e a harmonização de tôda atividade e esfôrço". (47)

Gulıck declara que "se a subdivisão de trabalho é indispensável, a coordenação é obrigatória". (48) MOoNEY acentua também a importância da coordenação; afirma êle, de fato, que todos os outros princípios de organização "estão contidos neste". MOONEY define a coordenação como "a distribuição ordenada do esfôrço do grupo, a fim de obter unidade de ação na consecução de um fim comum". (49)

Gulıck acredita que existem, em princípio, duas maneiras - que não se excluem, mas sim que se completam - de coordenar uma emprêsa: pelo fluxo das ordens emanadas, do supericr ao subordinado, seguindo as linhas de autoridade; e pela criação, na mente e na vontade dos que trabalham em grupo, de uma inteligente unidade de propósito. O primeiro método constitui a coordenação por organização, o segundo a coordenação pela dominância de uma idéia, (50) equivalendo à combinação do "esprit de corps" com a "unidade de direção" de FAyol. (51) Catheryn Seckler-Hudson afirma que a "unidade de.... propósito deve estar disseminada pela organização". (52)

O raciocínio de Mooney se assemelha a êste, ao declarar :

O poder coordenador, supremo.... é a autoridade; .... uma verdadeira coordenação deve ser baseada numa real comunhão de interêsses; a coordenação indica que há um alvo cu objetivo; doutrina... significa definição do objetivo.... cada membro de uma organização não deve apenas conhecer sua doutrina, mas deve sentí-la e absorvê-la até que viva em sua atmosfera e faça dela um guia de seus atos. (53)

São êstes os princípios aplicáveis à organização, de acôrdo com o ponto de vista dos "anatomistas". Antes de concluir êste capítulo, é necessário fazer referência a um último aspecto da organização de cima para baixo : seu conceito de função de "staff", a que Mooney chama a fase "staff" da funcionalização". (54)

FAYOL define "staff" como

um grupo de homens, munidos da fôrça, conhecimento e tempo que possam faltar ao administrador geral, de maneira a constituir complemento, refôrço e uma espécie de projeção da personalidade do administrador. (55)

(47) General and Industrial Management, p. 6.

(48) Notes on the Theory of Organization, "in Papers on the Science of Administration, p. 6 .

(49) The Principles of Organization, p. 5.

(50) Op. cit., p. 6.

(51) General and Industrial Management, pp. 25 e 40.

(52) Processes of Organization and Management, p. 43.

(53) The Principles of Organization, pp. 6, 9, 10 e 11.

(54) Ibid., p. 33.

(55) General and Industrial Management, p. 63. 
As palavras de Mooney são quase as mesmas :

Serviço de "staff" em organização significa serviço de recomendação ou conselho, que se distingue das funções de autoridade e comando... O "staff" constitui uma expansão da personalidade do. dirigente. Significa para êste mais olhos, mais ouvidos e mais. mãos que o auxiliem na formulação e na consecução de seus planos. (56)

E MOONEY acrescenta ainda :

Este serviço se desdobra em três fases que se apresentam perfeitamente correlacionadas: a informativa, a consultiva e a supervisora.... A fase informativa se refere aos elementos que a autoridade deve conhecer ao esquematizar - suas decisões; a consultiva serefere aos pareceres baseados naquelas informações; a supervisora consubstancia-se na aplicação das duas fases precedentes a todos os detalhes da execução. (57)

LEONARD WHITE apresenta argumentação semelhante :

Nas grandes organizações, outro tipo de especialização surge, apropriadamente denominado "o staff"....

O "staff" é um órgão de aconselhamento, para um dirigente categorizado, sem nenhuma responsabilidade executiva. A função exercida por um "staff" militar é planejar, aconselhar e assistir o. oficial comandante no comando, mas não comandar. A função de um "staff" civil é entendida da mesma maneira, ou seja, estudar os problemas administrativos, planejar, aconselhar, observar, mas não. agir. (58)

\section{AVALIAÇÃo DA CONTRIBUIÇÃo INDIVIDUAL NESTA ESCOLA}

Esta análise ligeira mostra, claramente, que a maioria das normas básicas. sugeridas por êste grupo foram estabelecidas por FAYOL e Gulick. Ambos tratam do assunto com clareza e exaustivamente, embora divirjam bastante, quanto à maneira de o encarar: FAYOL é o engenheiro que se transformou com sucesso num administrador e é sobretudo o homem prático tentando estabelecer as bases de uma teoria administrativa. Seus princípios de administração, contudo, carecem de apresentação metódica; muitas vêzes apresenta-se muito enfático e mesmo dogmático em seus esforços para provar o acêrto de suas ppiniões. Acentua-se isto no fim de sua vida, conforme se pode observar comparando a Administração Inđustrial e Geral, primeiramente publicada em 1916, com sua conferência pronunciada, em 1923, no Congresso de Ciências Administrativas de Bruxelas e incluída na coleção Ensaios sôbre a Ciência de Administração (Papers on the Science of Administration). FAYoL, contudo, destaca-se como autêntico pioneiro do estudo da administração de cima para

(56) Op. cit. pp. 33-41.

(57) Ibid. p. 33.

(58) Introduction to the study of Public Administration, pp. 30-31. 
baixo. Com seu "princípios de administração", complementados pelo estudo dos elementos da administração, lançou as bases para uma concepção teórica do assunto. Muitos de seus "princípios" resistem melhor à crítica do que muitos sugeridos mais tarde, por outros componentes do grupo; tanto assim que vários dos seus princípios soam hoje come truísmos.

Gulick é o erudito "par excellence". Suas Notas sôbre a Teoria da Organização são metòdicamente apresentadas, sua análise é sempre lógica; raramente é êle dogmático. Na realidade, as únicas indicações de dogmatismo encontram-se na sua discussão da unidade de comando e do alcance de contrôle, dois conceitos que têm sido objeto de crítica por parte de outras escolas de organização. O estudo de Gulick sôbre organização é bem mais completo que 0 de FAYOL. GuLICK não só abrangeu tôda a parte tratada por FAYOL como ainda apresentou uma vasta contribuição original. Sua análise da divisão do trabalho, sua teoria sôbre a departamentalização e suas idéias a respeito da coordenação são particularmente esclarecedoras.

A FAyol e Gulick segue-se Mooney, como grande inovador da teoria da organização. Embora não conhecesse o trabalho de $F_{A Y O L}$, suas principais idéias são semelhantes às dêste. Contudo, divergem os dois profundamente quanto aos métodos aplicados para discussão de seus conceitos. FAYOL é bastante empírico enquanto MoONEY tem uma formação mais científica. Na realidade, algumas vêzes procura êste de tal maneira ser científico que sacrifica a clareza à lógica, como no caso de sua tentativa - não analisada aqui - de enquadrar seus "princípios de organização" nas leis básicas da lógica, segundo L. ANDERSON. (59) A mais interessante parte de seu livro, contudo, a que descreve os princípios de organização através da história, (60) foge aos objetivos desta tese.

Em seguida vem URWICK, que raramente apresenta algo de novo, mas que foi o primeiro a fazer uma análise completa das contribuições de FAYOL, MOONEY e TAYLOR para a teoria de organização. URWICK compartilha com MOONEY a devoção por um esquema rígido e lógico; entretanto, mostra-se ineficaz nesse ponto, mais ainda do que MOoNEY, tanto assim que a maior falha de sua apresentação dos "princípios e métodos de crganização" (61) reside, exatamente, em não conseguir enquadrá-los num esquema lógico e convincente.

Não obstante, esclareceu muitos pontos em tôrno dos quais seus colegas tinham sido bastante obscuros, e muitas vêzes estabeleceu ligação entre êles.

Pertencendo a uma categoria diferente de FAYOL, URWICK, MoONEY e GuLICK - que acertadamente podem ser considerados os fundadores desta escola - encontram-se Wallace, Catheryn Seckler-Hudson e Henry NILES. Concentraram-se êstes no desenvolvimento e esclarecimento dos conceitos de seus predecessores, $a$ que em grande parte conseguiram. Todavia, tam-

(59) The Principles of Organization, pp. 45-46; o livro de ANDERson é "Das Losische". Seine Gesetze und Categorien.

(60) Ibid., pp. 47-164.

(61) The Elements of-Administration, pp. 35-76. 
bém êles acentuaram a tendência, nascida com a própria "escola anatômica", de pensar em Organização em têrmos formais e abstratos, sem dar muita atenção ao seu conteúdo psicológico e social. Isto constitui o que DWIGHT WALDo chama de "racionalismo" na teoria organizacional, de acôrdo com a qual

uma boa estrutura organizacional é aquela que se ajusta a um esquema adequado de boa organização, a que se adapte aos tipos renitentes de mentalidade, encontrados entre todos os indivíduos em tôdas as épocas, em vez de procurar atender às características e peculiaridades dos indivíduos que ocorre "habitarem" a organização numa determinada ocasião. (62)

Está é também a principal razão do "pronunciamento de Srmon contra grande parte da literatura em tôrno de assuntos administrativos". (63)

Diz êle :

A análise de administração sofre atualmente dos males da superficialidade, da supersimplificação e da falta de realismo. Confinou-se estritamente ao mecanismo da autoridade e não conseguiu colocar dentro de sua órbita os outros aspectos igualmente importantes que influenciam o comportamento da organização. Recusouse a atacar a tarefa cansativa do estudo de com quem devem ficar as atividades de tomar decisões. Tem-se contentado em falar de "autoridade", "centralização", "alcance do contrôle", "função", sem procurar definir êsses têrmos em função das operações. Se a análise da administração não atingir um nível mais alto de sofisticação, há pouco motivo para esperar que se obtenha rápido progresso na identificação e confirmação de princípios de administração válidos." (64)

E bastante curioso que seja FAYOL menos culpado do formalismo e do abstracionismo existente na tecria de organização do que outros que, como êle encararam a organização sob o ângulo "anatômico". Por ter sido incapaz de isolar o fator "estrutura" do fator "pessoal" - no que foi criticado por URWICK - deixcu de ser tão "racionalista" quanto seus colegas. Pergunta-se, teria sido FAYOL mais sábio que os outros ao adotar um conceito de organização que, de acôrdo com URWICK, "limita seu pensamento"? Teriam suas idéias sido diferentes se acontecesse ter êle vivido ao tempo de URWICK? Existe no trabalho de FAYOL base para uma suposição - não mais que isso - a respeito desta última hipótese: seu interêsse pela formulação racional de uma teoria de administração poderia tê-lo levado a isolar "estrutura" de "pessoal", tivesse êle vivido na década dos 30 , quando a discussão sôbre teoria organizacional foi em grande parte conduzida naquele sentido.

Mas será o rótulo de "racionalista" um título, indigno para esta Esccla?

(62) Ideas and Issues in Public Administration, p. 83.

(63) Administrative Behavior, p. 36.

(64) Ibid., p. 38. 
O eminente LEONARD WHITE assim não pensa, pois escreve, claramente :

Um sistema de administração, visto do ângulo especial de sua estrutura, constitui um agregado de cargos e ccupantes interrelacionados. E relativamente estável e existe em geral com o fim de satisfazer, para a comunidade, necessidades permanentes e continuadas. E racional, e não intuitiva e estabelecida ao acaso. Baseia-se em considerações gerais e não individuais. Os indivíduos entram e saem, mas a organização mantém sua própria vida; muitas já são antigas, mas a não ser em caso de catástrofe ou colapso, continuarão indefinidamente. As organizações tornam-se mais altamente especializadas à medida que crescem, mas tôdas as suas partes componentes baseiam-se no objetivo e nas funções. Sua espinha dorsal é a hierarquia e a aceitação da relação-superior-subordinado em arranjos mútuos de autoridade, responsabilidade e obediência. (65)

(Continua)

(65) Introduction to the Study of Public Administration, p. 39. 